Hidden agendas, social norms and why we need to re-think anti-corruption

Claudia Baez Camargo

Nikos Passas 
Basel Institute on Governance Working Paper 22. ISSN: 2624-9650.

Dr Claudia Baez-Camargo, University of Basel, Basel Institute on Governance, Steinenring 60, 4051 Basel, Switzerland claudia.baez-camargo@baselgovernance.org

Prof Nikos Passas, Northeastern University, 360 Huntington Ave, Boston, MA 02115, USA

n.passas@neu.edu

(c) Basel Institute on Governance, June 2017

Responsibility for the views expressed and for any errors of fact or judgment rests with the author alone.

This paper has been presented at the OECD Global Anti-Corruption \& Integrity Forum 2017 in a form of a poster presentation. 


\section{Hidden agendas, social norms and why we need to re-think anti-corruption}

Claudia Baez Camargo*

Nikos Passas** 



\section{Table of contents}

1. WHAT IS THE PROBLEM? 9

\section{WHAT DOES THE EVIDENCE TELL US? 10}

2.1 Informal governance practices among elites 10

2.2 Community norms and the social acceptability of corruption 12

2.3. What can we learn from the success stories? 14

3. WHAT HAVE WE BEEN DOING WRONG? 

This paper was submitted as part of a competitive call for papers on integrity, anti-corruption and inclusive growth in the context of the 2017 OECD Global Anti-Corruption \& Integrity Forum.

The research projects discussed in this paper are funded by UK aid from the UK government. However, the views expressed do not necessarily reflect the UK government's official policies.

Project "Informal Governance and Corruption - Transcending the Principal-Agent and Collective Action Paradigms" is funed by the joint UK Department for International Development (DFID) and British Academy Anti-Corruption Evidence (ACE) Programme.

Project "Corruption, Social Norms and Behaviours in East Africa" is funded by the East Africa Research Fund of DFID.

The authors thank Mr Marius Hochstrasser of the Basel Institute on Governance for providing comments and editorial support during the writing of this paper.

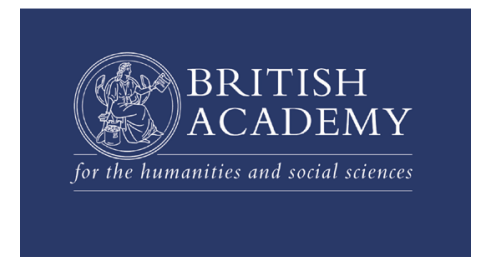

\section{EARF}

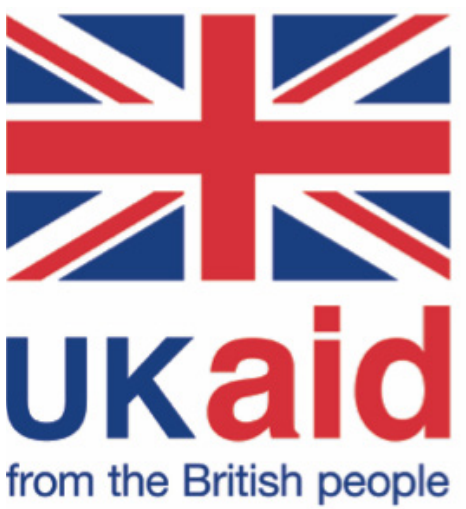





\section{What is the problem?}

Despite very substantial investments in anti-corruption, progress is frustratingly limited and in some cases insignificant. The resources devoted to the issue in the last fifteen years have been sizable, stemming from intense activity on the part of multilateral organisations, bilateral donors and private companies across numerous countries. These efforts have focused for the most part on ensuring the implementation of the OECD and UN conventions as well as regional instruments, building capacity, providing technical assistance and offering educational programs to the point one can speak of the emergence of a veritable "anti-corruption industry". Given that the anti-corruption agenda is frequently and correctly linked to those of rule of law, good governance and sustainable development, the funds and human capital applied to this issue are even more significant.

Against this background, one would expect to find measurable progress, reflected in an important reduction in the levels of corrupt activity around the world. Yet, in reality the results are deeply disappointing: Transparency International's Corruption Perception Index scores for sub-Saharan African countries, where many projects have focused, have worsened since the start of the "anti-corruption eruption". Global Integrity reports tell us that even when laws and reforms are introduced, their implementation is inadequate. Furthermore, in many countries anti-corruption laws are weakly or inconsistently implemented, sometimes even used as an instrument to target political opponents or simply applied only in cases of minor offenses involving low-level officials, leaving grand corruption crimes unpunished.

The lack of effectiveness of conventional anti-corruption interventions is thus quite clear (Mungiu-Pippidi 2011, 2015) and is reflected in the implementation gap, whereby countries that have committed themselves to legal and organizational reforms as well as the implementation of anti-corruption best practices continue to experience very high levels of corruption. Mungiu-Pippidi (2011) has also noted the paradox of how scores on the control of corruption keep worsening, even as the United Nations
Convention against Corruption gets ratified and specialized anti-corruption authorities are instituted by an increasing number of countries. Especially worrisome is how this lack of progress is also being reflected in the mood of people globally, as disappointment and demoralization lead to declines in institutional legitimacy (from the trust in the EU and national governments to particular politicians and the media) and consequently resulting in fertile grounds for populist politicians, who promise dramatic (though not necessarily realistic or desirable) changes to the political and economic systems to break the cycle of corruption (Heinrich and Transparency International 2017).

The lack of progress demands that we conscientiously rethink the way in which we formulate our anti-corruption approaches. In this paper, we make the argument that a new generation of more effective anti-corruption strategies can only be adequately developed through an evidence based understanding of the actual conditions prevailing in the countries where we want to support the fight against corruption. This involves delving into the contextspecific factors that account for the observed high levels of corruption as well as for the lack of effectiveness of mainstream approaches. 


\section{What does the evidence tell us?}

The arguments presented above indicate that we need to collect empirical evidence to better understand those cases notoriously characterised by the persistence of widespread corruption. The argument is that we need to take a closer look at how things actually happen, independently of how we would expect state institutions to perform according to good governance logic. Relevant questions include, therefore: How are decisions made across the public sector and by whom? What are the context-dependent considerations that shape the choices and behaviours of key national actors? How is corruption understood and experienced by average citizens?

In this section we discuss emerging findings from two on-going research projects of the Basel Institute's Public Governance Division. ${ }^{1}$ Adopting an inductive approach, this research has aimed to identify those practices and norms that are effective in "getting things done" (e.g. solving problems, attaining desired outcomes) and are thus commonly employed by local actors and stakeholders topdown (on the part of political and business elites) as well as bottom-up (on the part of citizens). ${ }^{2}$ In doing so, we have uncovered unwritten rules and behavioural patterns that articulate informal governance regimes, which are

1 The first project, entitled "Informal Governance and Corruption Transcending the Principal-Agent and Collective Action Paradigms" is funded by the joint UK Department for International Development (DFID) and British Academy Anti-Corruption Evidence (ACE) Programme. For more information about the ACE programme and the project please visit http://www.britac.ac.uk/anti-corruption and http://www.britac.ac.uk/node/4660 The second project is entitled "Corruption, Social Norms and Behaviours in East Africa" and is funded by the East Africa Research Fund of DFID. For more information about the EARF and the project please visit http:// www.earesearchfund.org/ and http://www.earesearchfund.org/ research-corruption-social-norms-and-behaviors-east-africa

2 Informal practices that are socially prevalent and entrenched abound around the world as documented by the vast database compiled by the Global Informality Project (http://in-formality.com/). Understanding of their varied impacts on development outcomes remains a key consideration in guiding future research. associated with a high prevalence of corruption.

The evidence coming out of the research suggests that there are at least two areas that formal anti-corruption strategies do not address and which are critical to develop more effective approaches, namely uncovering hidden agendas and tackling the habits of corruption.

\subsection{Informal governance practices among elites}

The arguments about top-down informal governance practices stem from research based on a comparative design involving seven countries from East Africa and Central Asia and the Caucasus. The sample includes five "challenging" cases - Kazakhstan, Kenya, Kyrgyzstan, Tanzania and Uganda where corruption remains endemic despite the introduction of adequate laws and institutional arrangements. The other two countries - Georgia and Rwanda - represent success stories, where control of corruption has recorded significant success. ${ }^{3}$

We have identified three distinct patterns of informal governance practices that are associated with high levels of corruption (Baez-Camargo and Ledeneva 2017):

- Co-optation is associated with recruitment or strategic appointments into public office of allies and potential adversaries, who are granted impunity in exploiting the power and resources associated to public office in exchange of mobilizing support and maintaining loyalty to the regime. ${ }^{4}$

- Control mechanisms are instrumental to manage clashes of hidden interests, ensure elite cohesion and enforce discipline of allies, which is why the unwritten rules of equivalent in the West as well (1997). 
co-optation depend on the existence of such informal control practices. Common examples involve the selective enforcement of anti-corruption laws against opponents or renegades, underscoring the validity of the saying attributed to Brazilian dictator Getulio Vargas: "for my friends everything and for my enemies the law". 5

- Camouflage refers to the manner in which the realities of political co-optation and control are hidden underneath institutional façades and policies consistent with a commitment to good governance and democratic accountability. Thus, punishment of a detractor may be accompanied by proclamations on the commitment to anti-corruption. ${ }^{6}$

The emerging evidence shows that informal practices in the challenging cases are pervasive; decisively shaping the in teractions among power networks of political and business elites and influencing how state actors relate to the general public. Numerous examples illustrate how these "three C's" are resorted to by political elites in authoritarian regimes to informally redistribute access to public resources along particularistic criteria, favouring networks of regime "insiders" at the expense of "outsiders". In fact, in the challenging cases, informal practices can be best characterised as instruments of governance associated with regime survival because they promote elite cohesion, nurture bases of support and weaken opponents.

These general findings can be illustrated in relation to the electoral process, whereby informal practices are utilised to secure favourable election outcomes through several routes as illustrated in Figure 1.

Figure 1: Informality, elections and corruption

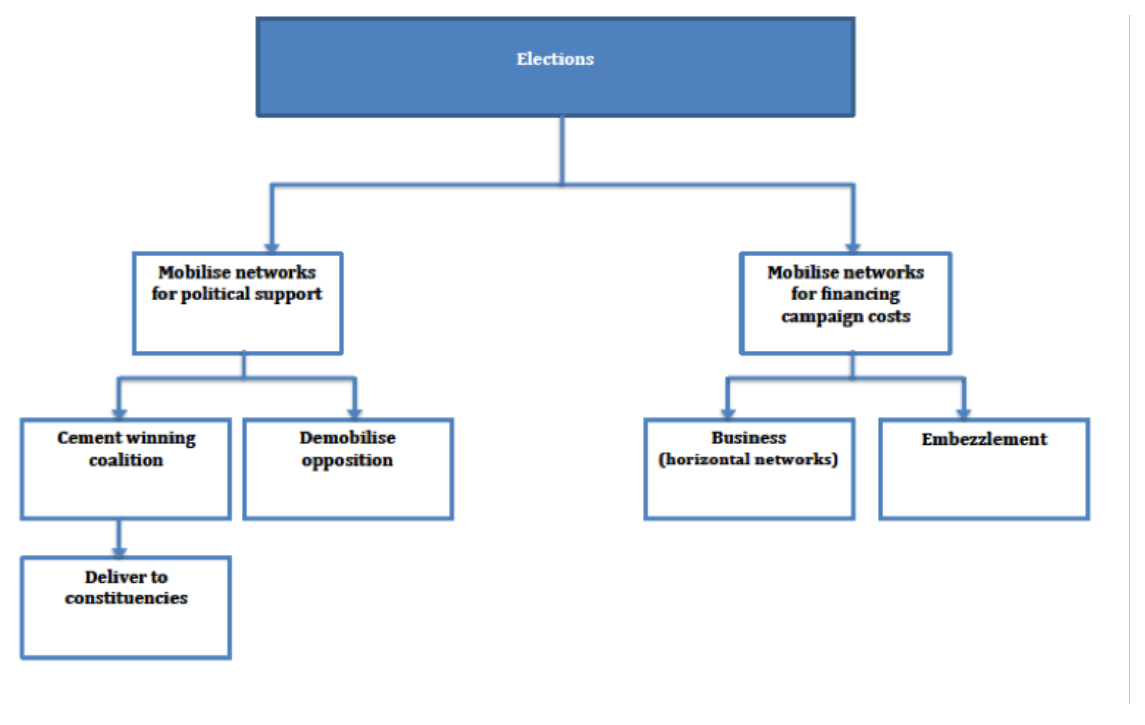

Source: Authors

5 See also Moroff and Schmidt-Pfister, 2010; for similar practices in cases of organized crime (Smith, 1990).

6 Studies of scandals and how they only scratched the surface are consistent also with the camouflage pattern (Neckel, 1989; Passas, 1996) or even the TV series "Yes Minister". 
First, informal governance mobilises political support and ensures elite cohesion by means of the selective distribution of goods, money and access to rents to supporters. Secondly, informal controls work to intimidate and obstruct the activities of opposition forces, for example through mobilisation of co-opted networks in the law enforcement sector or camouflaged via the selective application of laws related to national security.

Informal governance practices are also often utilised to mobilise co-opted members of informal networks in order to secure the financial resources that are needed to fund electoral campaigns, but also to buy votes and other activities geared at securing favourable outcomes. A common pattern involves collusion with influential coopted business interests that provide financial resources to political elites during elections in exchange for privileged financial rewards such as large government contracts and informal tax exemptions. Also, several grand corruption scandals -such as the Richmond scandal in Tanzania and the Goldberg scandal in Kenya- have been associated with the intention to divert large sums for electoral purposes.

All in all, the emerging evidence strongly suggests that in competitive authoritarian regimes informal practices around elections are frequently employed and are associated not only to political corruption but also to economic crimes. Overall, we find that the gap between the formal rules of democratic governance and commitment to anti-corruption and the actual informal practices of authoritarian survival via electoral manipulation and particularistic re-distribution of public resources is enormous. Furthermore, it appears in fact that discrepancy between the formal and the informal is a key factor enabling the corrupt to hide their deeds deep under the camouflage of the legal order.

These findings force a reflection on how informal governance compromises the effectiveness of the legal instruments typically involved in the fight against corruption. If corruption is indeed associated to the strategies of regime survival, then it follows that the enforcement of the anti-corruption framework is impracticable from the perspective of entrenched authoritarian elites as it entails undermining their bases of support.

\subsection{Community norms and the social acceptability of corruption}

From the bottom-up, our research at the grassroots level seeks to uncover the factors that influence attitudes towards petty corruption among citizens in Tanzania and Uganda - where petty corruption is widespread - as well as in Rwanda, where petty corruption has been for the most part effectively eradicated. ${ }^{7}$ Overall, the research points to the role that social norms and understandings play in fuelling and perpetuating positive attitudes towards corruption.

Just as the top-down analysis indicates that informal governance responds to the interests of networks of political and business elites, the research at the community level in Tanzania and Uganda reveals the salience of informal social networks as valued problem-solving resources for citizens. Informal social networks provide group solidarity and pooling of resources benefitting the group members and helping people cope with the difficulties of life generally, but also with deficient public service provision and widespread corruption in state institutions.

Research participants have described how typically any individual may be part of multiple networks. In a first instance there are the networks comprising family and friends. At a next level come the networks that include more distant acquaintances such as school peers, colleagues and neighbors. However, networks may also be very fluid and constructed instrumentally which means they can include individuals even more far removed from each other. As one commentator remarked, "when you have a problem and you do not have people to help you with it, then you go ahead and build the network to the person who can help you".

7 The case of Rwanda is discussed below in section 2.3. 
What makes such informal social networks relevant to our research is that they generate strong moral imperatives, including a sense of obligation to provide mutual assistance and reciprocity for favours given, which go above and beyond any consideration for the formal legal framework. This may very well be the strongest social norm found in the research so far.

Especially noteworthy is that the obligations vis-à-vis the network cut across the public/private divide, which means that in practice the networks hold strong expectations that any member who has a position in the public sector has the duty to utilize that position for the benefit of the network. These are examples of what we have termed "bottom-up cooptation" because the network co-opts the member holding public office into servicing the interest of the group. From the perspective of the public official, the pressure to engage in corrupt activities is tremendous not least because fulfilling the duties and obligations vis-à-vis the network is closely linked to social status.

Thus, according to research participants in focus group discussions in Kampala and Dar es Salaam, the corrupt individual who delivers to his or her group becomes " rich and thus admired", "popular and respected" or "a patron". Conversely, focus group participants reflected on the consequences for individuals refusing to engage in corruption in terms such as: "you will be shamed and disrespected", "you will be hated by associates", "you may be killed”, "people around you will make you fail”.

This social acceptability of behaviours that would legally classify as corrupt is linked to locally held understandings that actions benefitting "one's own people" are inherently just. In this sense, the research reveals how the determination of what is socially correct versus what is formally reprehensible is articulated in a continual and fluid evaluation of the particular circumstances surrounding each act rather than on rigid standards of ethical behavior stemming from a clear distinction between the public and private realms.

This latter point is well illustrated in the distinction that research participants in Tanzania and Uganda make between bribing and corruption. A bribe is generally understood as instrumental and deliberate; it is a way to get what people need and it is used pragmatically. Corruption, on the other hand, is understood to refer strictly to what we conventionally associate with grand corruption, involving large amounts of money and usually perpetrated by high level officials and influential individuals. Overall, tolerance towards bribing is considerably higher than it is towards acts of corruption because bribing is simply viewed as one of the many strategies that ordinary citizens are forced to resort to in order to solve the problems they are confronted with, from the life threatening (e.g. obtaining emergency medical treatment) to the ordinary (e.g. processing a drivers' license). Conversely, corruption is seen as stemming more directly from greed, an intrinsically individualistic act involving an abusive predisposition on the part of those who engage in it.

Thus, although among respondents in Kampala and Dar es Salaam bribing is for the most part pragmatically accepted, there are nonetheless unwritten rules that determine whether any particular act is deemed tolerable or not. Research participants agree that bribing should not be "excessive" and should not be extorted out of a desperate situation. Rather, bribing is often understood in terms of a broader social context in which individuals share a common understanding of each other's circumstances. Consequently, each transaction involves some measure of calculation. For instance, public service users often take into account the fact that service providers are most of the time paid low salaries and overworked. Such considerations mean that bribing can be seen as a win-win situation for both parties, whereby the user can solve a problem (perhaps avoiding a significant fine) and the service provider gets some help in making ends meet. The instrumentality of bribing is shown in that users may even recommend service providers who solicit bribes "reasonably" to their friends and acquaintances.

As mentioned before, whether a certain act, such as embezzlement of public funds, is tolerated or condemned depends on how the circumstances surrounding it are judged 
and by whom. Overall, the insights shared by the research participants suggest one same corrupt action will be accepted when it is meant to benefit the perpetrator's group and condemned when they are perceived to stem out of individual greed. Attitudes towards corruption are therefore infused with normative ambivalence or a pervasiveness of double standards, whereby one set of standards may apply to one's group and another set of standards to others (Ledeneva, 2017; Passas, 1997).

In sum, the research findings illuminate how social interactions based on deeply held values, such as reciprocity and solidarity, can be conducive to the social acceptability of corruption. Also notable is the underlying judgment about the fairness of each act, which is independent of whether the act contravenes or upholds the law. Thus, the gap between the formal and the informal is sustained on strong value laden beliefs where most research participants view the enforcement of the law as penalizing people whereas "bending" the laws is justified when it is done in order to help others, redress grievances and fulfil unmet needs. Acting with integrity is in these contexts not understood in terms of upholding the duties of public office or acting for an abstract public good, but rather caring after the particular interests of one's informal networks.

\subsection{What can we learn from the success stories?}

Georgia and Rwanda are success stories in the fight against corruption and in our research we have sought to understand the factors associated with their success from the perspective of what we have learned about the informal practices that drive corruption in the challenging cases.

Both countries have implemented radical reforms of the public sector. The reform packages involved, among other things, a drastic reconfiguration of their bureaucracies, dismantling existing discredited institutions and replacing them with new ones based on principles of leaner bureaucracies and administrative simplification. The specific elements of the reforms in Georgia and Rwanda have been extensively described elsewhere (e.g. World Bank 2012, Hausman 2014) but overall they included many of the approaches and tools of public sector reform associated with internationally recognised best practices (World Bank and Webb 2008).

In the findings, two dimensions of the public sector reform effort stand out. The first has been a stringent enforcement of the new rules based upon effective monitoring mechanisms and little to no tolerance to deviations, which has dramatically decreased the opportunity space to engage in the informal practices associated to corruption. Secondly, there has been a notable improvement in the ease of access to and quality of public services which, from the bottom up perspective, renders the resort to instrumental practices of bribing unnecessary and does away with the need to rely on informal networks.

Naturally the question arises about how the political will to implement far-reaching reforms comes about and why it appears to be absent in the challenging cases. The evidence suggests that the answer has to do with the nature of the leadership. Albeit stemming from radically different circumstances - the democratic election of the Georgian United National Movement in 2003 triggered by the events of the Rose Revolution and the military victory of the Rwandan Patriotic Front that put an end to the genocide in 1994 - in both countries a new leadership came to power that enjoyed autonomy from informal ties and obligations to the networks associated with the previous regimes and was backed by an overwhelming popular mandate. This seems to be key since the evidence from the challenging cases suggest that radical reforms are extremely difficult (if not impossible) to undertake when the leaders depend for political support on extensive clientelistic and patronage relationships, which in turn depend on the availability of a large number of public sector positions and resources.

Rwanda further offers important lessons that demonstrate how anti-corruption can be tailored to specific contexts. In particular, a central feature of the Rwandan anti-corruption 
crusade relates to a deliberate effort to close the gap between informal norms and the formal legal framework. Two modalities are observable by means of which better alignment between the formal and the informal have been pursued.

The first modality involves "formalising the informal" or, perhaps even better, "respecting and drawing on the informal" or developing formal policies that are closer to social norms and practices to which ordinary citizens easily relate. This is best illustrated with reference to the so-called home grown initiatives, which are policies and government initiatives that appeal to traditional Rwandan social norms and values. An illustrative example of these home grown initiatives, which has been effective in controlling corrupt behaviours in the public sector, is the imihigo or performance contracts that are signed by every public official (and now even by heads of households) whereby they commit to achieving a set of performance goals associated with government development programs, to which they are later on held accountable. The origin of the imihigo in Rwandan traditional culture refers to a commitment of bravery, patriotism and service to the community that would go as far as to require the sacrifice of one's life if so required. In the case of high level functionaries at both the local and national government levels, the performance contracts are signed directly with the President. Furthermore, the bi-annual evaluation meetings are chaired by the President and strongly echo the traditional guhigura imirimo or kwivuga ibiwi public "praise ceremonies" where successful contenders were publically eulogized for their bravery before the community leaders. Nowadays, the performance evaluation process receives extensive coverage across the country and while the best performers are rewarded, the research suggest that failure to meet one's targets is considered to be an immense dishonour that brings shame not only to the individual but also to his or her family and community.

The second modality involves emphasising education and awareness raising activities that seek to promote expectations, values and mental models consistent with the rejection of corrupt behaviours. In this sense, the Rwandan regime has given strong emphasis to the promotion of integrity as a value associated to the national identity, which appears to be effective in cultivating socially accepted values closer to those of the rule of law and good governance paradigm. Of particular relevance are training programs such as Itorero, which in the history of Rwanda was the school of excellence for Rwandan youth who were trained at the King's palace on moral and intellectual skills as well as military training to develop virtues of courage, patriotism, endurance, and public responsibility. The Itorero Civic Education Program was reintroduced in 2007 and consists of instruction on Rwandan history that emphasizes traditional cultural values that translate into strong commitment to public service and good governance in the contemporary setting. Notably, our research suggests that attending Itotero has become a source of social status among Rwandans whereby alumni are looked up to and respected in their communities.

The effectiveness of these measures to counter corruption top-down is reflected in our findings from the research at the grassroots level in Rwanda where it is recognized that it is extremely difficult to get away with bribing and that the penalties that can be expected if caught are very harsh for both the receiver and the giver. In the focus group discussions in the urban area (Kigali) participants gave numerous examples of people they know who ended in prison for paying a bribe even if the amount involved was small. In Rwanda it is simply assumed that in the current context one cannot get away with behaving corruptly. 
On the face of emerging evidence about contextual drivers of corruption, what can be said about the shortcomings of conventional anti-corruption approaches?

The evidence supports the notion that in the challenging countries the problem of widespread corruption is best characterised as a collective action problem, where the absence of a "principled principal" that has the incentives to forcefully pursue an anti-corruption agenda is conspicuous (Persson, Rothstein, and Teorell 2013). However, rather than attributing the collective action dilemma to shared expectations that everyone else behaves corruptly, evidence from the challenging cases suggests that what lies beneath are complex systems comprised of interwoven informal political and social networks that operate away from formal settings. The roots of corruption lie in the informal strategies by means of which political elites, business interests and social actors acquire power and resources. When those informal strategies are effective, they become entrenched, acquiring systemic dimensions. In such contexts, anticorruption approaches that treat corruption as exceptional - as opposed to generalized - behaviour will, not surprisingly, have limited success.

From the arguments above it follows that a major challenge to the effectiveness of mainstream anti-corruption technical assistance is that it does not take into account the evidence that corruption is widespread and embedded because it is functional. It helps win elections, reward supporters, control opponents and gain access to resources. At the political level, where practices of co-optation, control and camouflage are used instrumentally to stay in power and ensure the stability of authoritarian regimes, the top leaders themselves become hostages of the particularistic interests on whose support they rely. Such cases depend on corruption for legitimation and ultimately for survival. In turn, average citizens, who indeed suffer the consequences of corruption, are not necessarily innate advocates of anti-corruption but rather may go to great lengths to bypass if not outright break the law (Passas, 1990, 2000, 2010). The evidence from East Africa highlights how unmet needs are a powerful force behind the tolerance to corrupt practices because it reveals that bribes and networks serve similar functions: they are tools to "get things done".

Thus, it seems an inescapable conclusion is that more effective anti-corruption strategies will need to address the functionality of corrupt practices from the perspective of those who engage in them. The Rwandan case is an example of how an improved provision of public services contributes to render bribing and use of informal influences unnecessary. The Georgian case suggests that democratic competition can bring to power a new independent leadership capable of assuming the role of a principled principal and enforcing radical reforms.

The functional relevance of informal practices also points to the problems with the tendency to address corruption by means of adopting tougher formal laws. An adequate legal framework is, of course, essential and necessary, but laws must also be supplemented with other approaches that address the root causes of corruption. Too many lawyers and bureaucracy in the design and implementation of governance reforms result in symbolic legal mechanisms that have little impact on the incidence as well as perception of corruption.

Furthermore, a purely legalistic approach generates certain risks. In both government and the private sector, misalignment of legal practice and ethical norms results in mere-law-based compliance and "lawful but awful" practices (Passas, 2005). Furthermore, the "regulatory tsunami" facing governments around the world, which are tasked with implementing multiple international conventions, generates intense legislative and regulatory activity that risks generating excessive red tape, and regulatory complexity as well as normative ambiguity, which generate incentives for circumvention of rules and corrupt practices (Claro and Passas, 2013). Indeed convoluted legal frameworks provide an ideal ground for camouflaging corrupt dealings (Baez Camargo and Ledeneva, 2017), which means that not carefully crafted legal reforms may ironically undermine anticorruption objectives as well as overall governance, rule of law and legitimacy. 


\section{What have we been doing wrong?}

It is unquestionable that anti-corruption measures can be externally induced, through the adoption of international conventions, the actions of international and bilateral organizations, and as reactions triggered by corruption perception indices or hastily adopted metrics. While to a large extent governments may pursue anti-corruption efforts out of a genuine belief in the rule of law, it should also be recognized that reforms can also be passed merely to appease international donors and investors, as an instrument of legitimization vis-à-vis external and internal audiences or as a weapon against political opponents. In such contexts anti-corruption in the form of technical assistance to law enforcement agencies risks making the camouflage façade thicker by providing proof of a commitment to anti-corruption that may not be entirely genuine.

There are problems as well with conventional protocols for the implementation of development assistance programmes. Informal governance systems cannot be addressed when the tasks and functions of anti-corruption work are conceived in a fragmented manner, as they often are, which in addition leads to an inefficient use of resources and thereby generate malfunctions (e.g. overlap of mandates conducive to turf wars, duplication of work and interferences). In this sense, linear approaches to implementing development programming that emphasize predefined outputs and results frameworks are increasingly recognized as problematic especially for anti-corruption programmes that operate in complex, politically sensitive and continuously changing environments (Adam Smith International 2016). Focus on interim goals and targets that different organizations "must meet" by internal or sponsor arrangements are sadly conducive to missing the ultimate goals of anti-corruption: culture of integrity, less corruption, better governance, services, quality of life, security, rule of law, sustainable economic growth/development and happiness in society. A narrow focus on specific projects and interim metrics risks losing sight of problematic activities (which are either taken for granted or as dismissed as "natural" and inevitable) preventing us from constructing widespread dysfunctions as social problems that must be documented, discussed and addressed collectively.
Finally, the need to contextualise is recognized on paper but is seldom reflected in "off the shelf" policies. This does not apply only to the case study countries from which the arguments in this paper are derived but to many others as witnessed by the cases of Afghanistan, Somalia and Greece (to name a few), which provide examples where resources have been wasted implementing costly changes that have failed to yield results (according to a recent report, the reconstruction of Afghanistan has cost more than the total post-war European reconstruction ${ }^{8}$ ).

These problems lie at the heart of the legitimacy and legality gap (Passas, 2005; Passas and Goodwin, 2004), a gap between what is right, ethical and acceptable on the one hand, and what is mandated by the law. This gap will never be bridged by an insistence on doing things in the same way as before, insisting on "solutions" that do not work, pretending that we can get better results in the future, creating unreasonable expectations and thus getting close to what might be termed "regulatory fundamentalism" (Passas, 2006, 2015). 


\section{Towards a new generation of anti-corruption strategies}

The evidence suggests that high levels of corruption are associated to a significant discrepancy between formal rules and informal practices. However, efforts to address such gap by passing additional laws not only do not work, but may actually compel the problem by incrementally pitting the formal and informal against each other. In fact, as the success cases imply, simplifying processes and rules is key since complex legal frameworks can better accommodate the camouflage of illegal actions. Furthermore, formal laws and policies can be drafted in a manner that they appeal to the prevailing social norms and values of the population and the educational sector has a critical role to play in supporting the development of a culture of integrity.

We conclude this paper by suggesting that anti-corruption practitioners might want to re-think the role of informality and consider how it may actually help us. The prevalence and entrenched nature of informal practices indicate their heuristic potential: they can tell us what we are missing in official policies, inform about resistances and can help uncover pathways to strategic, sustainable reforms. Thus, we need to be concerned with making the invisible visible by understanding the logic that underpins the workings of the informal regimes as a first step on the road to strengthening our ability to support better development outcomes.

A nuanced understanding of the political economy of corruption will help practitioners to recognise that in the "challenging" cases we are confronted with complicated systems comprising powerful and tightly interwoven interests, which calls for an evidence-based, systematic and collective response. A step in the right direction will be moving away from fragmented approaches and constructing multi-stakeholder coalitions capable of engaging in collective action on the basis of a long-term strategic approach. 


\section{References}

Adam Smith International. 2016. 'Thinking and Doing Anti Corruption Programming Differently'. Adam Smith International. https://issuu.com/adamsmithinternational/ docs/thinking_and_doing_anti-corruption_/1.

Baez-Camargo, Claudia, and Alena Ledeneva. 2017. 'Where Does Informality Stop and Corruption Begin? Informal Governance and the Public/Private Crossover in Mexico, Russia and Tanzania'. The Slavonic and East European Review 95 (1): 49-75. doi:10.5699/slaveasteurorev2.95.1.0049.

Carter, Timothy S. (1997). The Failure of Environmental Regulation in New York: The Role of Co-optation, Corruption and a Co-operative Enforcement Approach. Crime, Law and Social Change, 26, 27-52.

Claro, Jorge, \& Passas, Nikos. (2013). Effects of the Anti$\neg$ corruption Agenda on Public Procurement Practices. Washington DC.

Hausman, David. 2014. 'Rebuilding the Civil Service After War: Rwanda After the Genocide, 1998-2009'. Rebuilding the Civil Service After War: Rwanda After the Genocide, 1998-2009, July. /publications/rebuilding-civil-serviceafter-war-rwanda-after-genocide-1998-2009.

Heinrich, Finn, and Transparency International. 2017. 'Corruption and Inequality: How Populists Mislead People'. Www.transparency.org. https: / /www.transparency.org/news /feature / corruption_and_inequality_how_populists_mislead_people.

Ledeneva, Alena (2017) 'Key Challenges and Main Findings of the Global Informality Project' in Ledeneva, A. et al (eds.) 'Global Encyclopaedia of Informality. Vol.1. London: UCL Press

Moroff, H., \& Schmidt-Pfister, D. (2010). Anti-corruption movements, mechanisms, and machines - an introduction. Global Crime, 11(2), 89-98.
Mungiu-Pippidi, Alina. 2011. 'Contextual Choices in Fighting Corruption: Lessons Learned'. SSRN Scholarly Paper ID 2042021. Rochester, NY: Social Science Research Network. http: / / papers.ssrn.com/abstract=2042021.

Mungiu-Pippidi, Alina. (2015). The Quest for Good Governance: How Societies Develop Control of Corruption. Cambridge: Cambridge University Press.

Neckel, Sighard. (1989). Power and Legitimacy in Political Scandal: Comments on a Theoretical Framework for the Study of Political Scandals. Corruption and Reform, 4, 147-158.

Passas, Nikos. (2005). Lawful but Awful: “Legal Corporate Crimes”. Journal of Socio-Economics, 34(6), 771-786.

Passas, Nikos. (2015). The Hellenic Crisis: Regulatory Fundamentalism and Injustice. European Working Group on Organizational Crime Newsletter, 5(2).

Passas, Nikos. (2010). Anomie and White-Collar Crime. In F. T. Cullen \& P. Wilcox (Eds.), Encyclopedia of Criminological Theory (pp. 56-58): Sage.

Passas, Nikos. (2006). Setting Global CFT Standards: A Critique and Suggestions. Journal of Money Laundering Control, 9(3), 281-292.

Passas, Nikos. (2005). Lawful but Awful: “Legal Corporate Crimes”. Journal of Socio-Economics, 34(6), 771-786.

Passas, Nikos. (2000). Global Anomie, Dysnomie, and Economic Crime: Hidden Consequences of Globalization and Neo-liberalism in Russia and Around the World. Social Justice, 27(2), 16-44.

Passas, Nikos. (1997). Anomie, Reference Groups, and Relative Deprivation. In N. Passas \& R. Agnew (Eds.), The Future of the Anomie Tradition (pp. 62-94). Boston: Northeastern University Press. 
Passas, Nikos. (1996). The Genesis of the BCCI Scandal. Journal of Law and Society, 23(1), 52-72.

Passas, Nikos. (1990). Anomie and Corporate Deviance. Contemporary Crises, 14(3), 157-178.

Passas, Nikos, \& Goodwin, Neva (Eds.). (2004). It's Legal, but It Ain't Right: Harmful Social Consequences of Legal Industries. Ann Arbor: University of Michigan Press.

Persson, Anna, Bo Rothstein, and Jan Teorell. 2013. 'Why Anticorruption Reforms Fail-Systemic Corruption as a Collective Action Problem'. Governance 26 (3): 449-471. doi:10.1111/j.1468-0491.2012.01604.x.

Smith, Dwight C. (1990). The Mafia Mystique. Lanham, New York: University Press of America.

World Bank 2012. Fighting Corruption in Public Services: Chronicling Georgia's Reforms. World Bank. https:// openknowledge.worldbank.org/handle/10986/2234.

World Bank, and Steven Benjamin Webb. 2008. 'Public Sector Reform: What Works and Why?' Independent Evaluation Group Studies. http:/ / elibrary.worldbank.org/ doi/abs/10.1596/978-0-8213-7589-1. 


\section{Notes}




\section{Basel Institute on Governance}

The Basel Institute on Governance is an independent non-profit competence centre specialised in corruption prevention and public governance, corporate governance and compliance, anti-money laundering, criminal law enforcement and the recovery of stolen assets. Based in Switzerland, the Institute's multidisciplinary and international team works around the world with public and private organisations towards its mission of combating financial crime and tangibly improving the quality of governance globally.

\section{Working papers}

In this working paper series the Basel Institute on Governance publishes reports by staff members and invited international experts, covering critical issues of governance theory and practice. For a list of publications, please visit www.baselgovernance.org. 


\section{Abstract}

In many countries high levels of corruption persist in spite of the adoption of so-called anti-corruption "best practices". In this paper we make a call to pursue a context-sensitive inquiry into the drivers of corruption in order to substantially improve the practices and effects of anti-corruption. We discuss evidence from case studies in Africa, Central Asia and the Caucasus suggesting that high levels of corruption are associated to a significant discrepancy between formal rules and informal practices. Informal practices of co-optation, control and camouflage are used by political and business elites to safeguard regime survival via a de facto re-distribution of public resources in favour of informal networks of "insiders". From the perspective of citizens, corrupt acts such as bribing enjoy social acceptability especially when they are effective in solving practical problems and protecting livelihoods. The functional relevance of informal practices clarifies the factors behind the limited effectiveness of anti-corruption law-driven reforms, short-term action plans, and technical measures that focus on particular processes, procedures and institutions. We argue for the need to ponder informality and consider how it may help us develop better anti-corruption strategies. The prevalence and entrenched nature of informal practices indicate their heuristic potential: they can tell us what we are missing in official policies, inform about resistances and can help uncover pathways to strategic, sustainable reforms. 